\title{
Smartphone Addiction and Life Satisfaction: Mediating Effects of Sleep Quality and Self-Health
}

\author{
Jianfei $\mathrm{CAO}^{1}$, Yeongjoo $\operatorname{Lim}^{2} \&$ Kota Kodama ${ }^{1}$ \\ ${ }^{1}$ Graduate School of Technology Management, Ritsumeikan University, Osaka, Japan \\ ${ }^{2}$ Faculty of Business Administration, Ritsumeikan University, Osaka, Japan \\ Correspondence: Kota Kodama, Graduate School of Technology Management, Ritsumeikan University, 2-150, \\ Iwakuracho, Ibaraki, Osaka, Japan. Tel: 81-72-665-2448.
}

Received: December 12, 2020 Accepted: January 10, 2021 Online Published: January 13, 2021

doi:10.5539/gjhs.v13n3p8

URL: https://doi.org/10.5539/gjhs.v13n3p8

\begin{abstract}
As the popularity of smartphones grows, so does the number of people who are addicted to them. Although many studies have indicated that the various problems associated with smartphone addiction can negatively affect life satisfaction, this result is not absolute. This study surveyed 114 Chinese alumni of a Japanese university and analyzed the mediating effects of sleep quality and self-health on the relationship between smartphone addiction and life satisfaction. Results indicated that smartphone addiction did not affect life satisfaction, neither directly nor indirectly through sleep quality and self-health. This finding was different from those of previous studies. In addition, the results indicated that smartphone addiction directly affects sleep quality, and that smartphone addiction can affect self-health either directly or indirectly through sleep quality. Based on this finding, we believe that intervention in the excessive use of smartphones is an effective means to improve the physical fitness of people.
\end{abstract}

Keywords: life satisfaction, pls-sem, self-health, sleep quality, smartphone addiction

\section{Introduction}

Smartphones have certainly enriched people's lives; for example, their use in health management has become very common in recent years (Alwashmi et al., 2020; Bentley et al., 2020; Callan et al., 2020). However, like a doubled-edged sword, excessive reliance on smartphones may cause numerous problems in our lives. In fact, an increasing amount of people are unable to leave their smartphones. Considerable research has found that separation from a smartphone can cause anxiety (Konok, Pogany, \& Miklosi, 2017; Nie, Wang, \& Lei, 2020; Wilcockson, Osborne, \& Ellis, 2019), which is a typical feature of addiction (Shaffer, 1996). Smartphone addiction (SA) is a behavioral addiction. Although different to substance addiction, SA has similar characteristics such as an inability to control or limit the use of an external element despite being aware that this has significant harmful consequences (Shaffer, 1996). Moreover, studies show that SA has negative effects on various aspects of our lives, such as decreased quality of interpersonal interaction (Misra, Cheng, Genevie, \& Yuan 2016; Przybylski \& Weinstein, 2013) and decreased quality of sleep (Lanaj, Johnson \& Barnes, 2014; Lemola, Perkinson-Gloor, Brand, Dewald-Kaufmann, \& Grob, 2015; Munezawa et al., 2011). These negative effects may lead to a decline in life satisfaction. Presently, the effects of SA on life satisfaction are mostly related to psychological aspects, such as loneliness (Phu \& Gow, 2019) and anxiety (Lepp, Barkley, \& Karpinski, 2014), as psychological problems are important factors that reduce life satisfaction. However, few studies have explored the mediation effect of physiological factors. Therefore, this study made an attempt to explore the mediating role of sleep quality and self-health on the relationship between SA and life satisfaction.

\section{Theories and Hypotheses}

\subsection{Smartphone Addiction and Sleep Quality}

In the past few decades, we have witnessed the increasing availability of smartphones and their expanding functionality, including (amongst others) smartphone games, chat, and video playback. Such functions in a small smartphone may conveniently be enjoyed in bed. The 2011 American Sleep Survey found that $95 \%$ of the respondents used TV, computers, smartphones, and other electronic media before going to bed at least a few nights a week (National Sleep Foundation, 2011). However, the use of smartphones or other electronic media may 
shorten sleep time and lead to problems of insufficient sleep, such as difficulty falling asleep (Custers \& Van den Bulck, 2012; Tamura, Nishida, Tsuji, \& Sakakibara, 2017). Other studies have reported that media usage time is usually inversely proportional to sleep quality (Calamaro, Mason \& Ratcliffe, 2009; Fossum, Nordnes, Storemark, Bjorvatn \& Pallesen, 2014). Especially in developed countries with a high penetration rate of smartphones, excessive use of them is very common. A survey revealed that $81 \%$ of Americans use their smartphones throughout the day ("always on"), and on media devices, spend more time ( 8 hours and 41 minutes) than sleeping ( 8 hours and 21 minutes) (Davies, 2015). For those addicted to smartphones, their behavioral addiction may cause them to be more easily attracted to the various functions of the smartphone, thereby reducing their sleep time. A study by Adams and Kisler (2013) on college students found that $47 \%$ of the students reported that they would wake up at night to reply to text messages, and $40 \%$ reported that they wake up at night to answer the phone. Moreover, low sleep quality negatively affects people's lives and reduces life satisfaction. A study compared the differences in stress and life satisfaction of those college athletes who were sleep-deprived $(n=72)$ and those who slept well $(n=105)$. Results showed that college athletes with problems of sleep quality perceived more stress in their daily life and reported lower life satisfaction (Litwic-Kaminska \& Kotysko, 2017). Another study of 120 students in a Malaysian university showed that sleep quality scores were significantly negatively correlated with life satisfaction scores, indicating that better sleep quality (low scores) is associated with better satisfaction in life (high scores) (Zaid, Rahman, \& Haque, 2018). Sleep disturbance is a key risk factor of health problems such as incident hypertension (Cappuccio et al., 2007; Gangwisch et al., 2006; Gottlieb et al., 2006) and diabetes (Ayas et al., 2003; Cappuccio, D’Elia, Strazzlillo, \& Miller, 2010), Therefore, we set the following hypotheses:

Hypothesis $\mathbf{1}\left(\mathbf{H}_{\mathbf{1}}\right)$. Smartphone addiction has a direct effect on sleep quality.

Hypothesis $\mathbf{2}\left(\mathbf{H}_{\mathbf{2}}\right)$. Sleep quality has a direct effect on life satisfaction.

Hypothesis $3\left(\mathbf{H}_{\mathbf{3}}\right)$. Sleep quality has a direct effect on self-health

\subsection{Smartphone Addiction and Self-Health}

People who are addicted to smartphones are usually sedentary, and therefore tend to be underexercised (S. E.Kim, J. W. Kim, \& Jee, 2015); one of the most common negative effects of SA. In addition, because the use of a smartphone requires heavy utilization of the fingers and other palm muscles, a study reported that smartphone users have a higher risk of musculoskeletal diseases, manifested as pain in the thumb and forearm, and stiffness in the joints such as the wrist (Sharan, Mohandoss, Ranganathan, \& Jose, 2014). Other studies have found that bowing one's head for a long time to use a smartphone will cause the head to bend more and cause postural problems (Jung, Lee, Kang, Kim, \& Lee, 2016; Lee, Kang, \& Shin, 2015), such as pain in the shoulder and neck (Berolo, Wells, \& Amick, 2011). Additionally, one study compared the life satisfaction of patients with chronic, non-malignant musculoskeletal pain and that of the general population with results showing that the former reported lower life satisfaction scores than the latter. In other words, self-health may affect life satisfaction (Boonstra, Reneman, Stewart, Post, \& Preuper, 2012). Therefore, we set the following further hypotheses:

\section{Hypothesis $4\left(\mathbf{H}_{\mathbf{4}}\right)$. Smartphone addiction has a direct effect on self-health.}

\section{Hypothesis $\mathbf{5}\left(\mathbf{H}_{\mathbf{5}}\right)$. Self-health has a direct effect on life satisfaction.}

\subsection{Smartphone Addiction and Life Satisfaction}

Life satisfaction is a key indicator of subjective well-being. It is defined as the overall cognitive assessment of one's own living conditions most of the time or for only a certain period (Diener, Suh, Lucas, \& Smith, 1999). In society, it is an important parameter of people's quality of life. Most previous studies have shown that SA is inversely related to life satisfaction. For example, one study reported that excessive use of smartphones is the cause of users' low satisfaction with life (Volkmer \& Lermer, 2019). Although studies have shown that SA has a negative effect on life satisfaction, it does not seem to be absolute. Samaha and Hawi (2016) did not find a significant direct correlation between SA and life satisfaction, and their study showed that SA indirectly affected life satisfaction through the mediation of perceived stress. Another study indicated that although smartphone use is generally negatively associated with well-being, this is not always the case; a deeper analysis indicated that certain smartphone applications can have a positive impact on well-being (David, Roberts, \& Christenson, 2018). Consequently, further research is needed to clarify the relationship between smartphone dependence and life satisfaction. Therefore, we set the following hypothesis:

\section{Hypothesis $\mathbf{6}\left(\mathbf{H}_{\mathbf{6}}\right)$. Smartphone Addiction has a direct effect on life satisfaction}

\subsection{Model of the Present Study}

Based on our literature review, sleep quality and self-health could potentially mediate the relationship between SA 
and life satisfaction. Therefore, we created a multi-attribute model, presented in Figure 1.

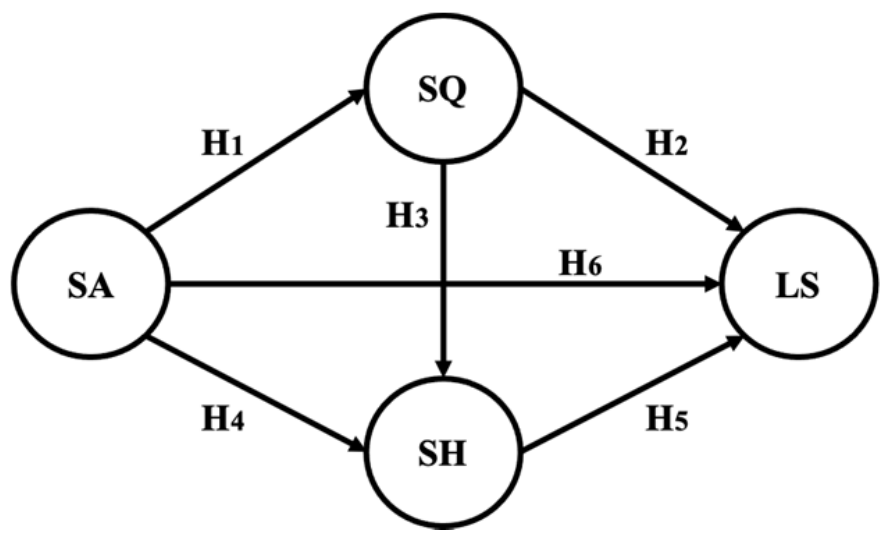

Figure 1. Models to be tested.

Note. SA: smartphone addiction, SQ: sleep quality, SH: self-health, LS: life satisfaction

\section{Method}

\subsection{Data Collection}

In this study, we conducted a three-day online survey through the WeChat application. We surveyed 499 members of the chat group of the Chinese Alumni Association of a university in Osaka, Japan from February 7 to February 10, 2020. The members had studied abroad in the same Japanese university (the campus may have varied). We provided the necessary information about informed consent to the respondents on the first page of the survey. Only if the respondents confirmed their consent, the complete questionaries would show on the next page. We obtained 120 responses (24\% response rate) and respondents participated voluntarily without any financial incentives. We further screened the data and deleted 6 incomplete response sets, and arrived at 114 valid responses, and an effective response rate of $95 \%$. In the questionnaire, participants were asked to report their self-assessments based on the previous month. The questionnaire consisted of five main parts: personal information, smartphone addiction scale, satisfaction with life scale, self-health scale, and sleep quality scale.

\subsection{Composition of the Survey}

\subsubsection{Smartphone Addiction Scale}

In order to measure the addictive behavior of smartphones, we used the "Smartphone Addiction Scale - Short Version (SAS-SV)" developed by Kwon, Kim, Cho, and Yang (2013). The original version, "Smartphone Addiction Scale (SAS)" was also developed by Kwon et al. (2013), which included 6 factors and 33 items identified through factor analysis. All items follow a 6-point Likert scale and adding the score for each item produces the total score; a higher score indicates more serious SA. However, due to the imbalance between males and females in the development of this scale, it is difficult to compare the differences in gender, it is impossible to use the critical value to assess the degree of addiction. In December 2013, Kwon and colleagues took the main concept of the smartphone addiction scale (SAS) as the evaluation object, developed the short version of the smartphone addiction scale (SAS-SV), and proposed dividing the critical value by gender. To shorten the previous version, seven experts in related fields were invited, including three psychiatrists, two nurses with a doctorate, and two psychologists with a doctorate to evaluate each item of the SAS. An item's relevance was scored on a scale of 1-4 (1: "an irrelevant item," 2: "unable to assess the relevance without item revision" 3: "relevant but needs minor alteration," and 4: "an extremely relevant item"). Finally, the scale was shortened to 10 items. The total score range is 10-60. It is clear that the threshold value is 31 for males and 33 for females. In other words, when the score is greater than or equal to this threshold value, the respondent is considered to be addicted to smartphones (Kwon et al., 2013). The scale has been used widely in various studies related to SA, and the internal consistency reliability was satisfactory (Dharmadhikari, Harshe, \& Bhide, 2019; Hughes \& Burke, 2018). Similary, in the subsequent model analysis, this scale also showed good internal consistency reliability (Cronbach's alpha $=0.881$ ).

\subsubsection{Satisfaction with Life Scale}

In this study, the Satisfaction with Life Scale developed by Diener et al. (1985) was used to assess participants' 
satisfaction with life. It is composed of 5 items and is evaluated on a 7-point Likert scale. The total score range is 5-35; a higher score indicates higher life satisfaction. There are cutoffs to be used as benchmarks: 31-35: extremely satisfied, 26-30: satisfied, 21-25: slightly satisfied, 20: neutral, 15-19: slightly dissatisfied, 10-14: dissatisfied, and 5-9: extremely dissatisfied. This scale is widely used by researchers, and it showed a high internal consistency in various studies (Jovanovic, 2016; Rezaei \& Jeddi, 2020). Likewise, this scale also performed well in this study's sample (Cronbach's alpha $=0.881)$.

\subsubsection{Sleep Quality Scale}

To determine the sleep quality of the participants, we used the Pittsburgh Sleep Quality Index (PSQI) (Buysee, Reynolds, Monk, Berman, \& Kupfer, 1989). The scale is suitable for the evaluation of sleep quality in patients with sleep disorders and mental disorders, along with the evaluation of sleep quality in ordinary people. The PSQI assesses the sleep quality of participants over the last month. It consists of 19 self-assessment items and 5 other-evaluation items (one of the five being a self-evaluation item but all five do not contribute to the final score). In this scale, seven subscales that affect sleep quality are evaluated. They are subjective sleep quality, sleep latency, sleep duration, habitual sleep efficiency, sleep disturbances, use of sleeping medication, and daytime dysfunction. Each subscale is evaluated using a 4-point Likert scale ranging from 0 to 3, and the score of each factor is added to arrive at the total score of PSQI. The total score range is $0-21$, the higher the score, the worse the sleep quality. In the model analysis, we considered the factors of each subscale as outer items to predict sleep quality. Model test results showed that the scale has good internal consistency reliability in this study (Cronbach's alpha $=0.741$ ).

\subsubsection{Self-Health Scale}

Currently there is no self-health scale for people with SA. Based on previous research (Kim et al., 2015; Sharan et al., 2014; Jung et al., 2016; Lee et al., 2015; Berolo et al., 2011), this study summarizes seven possible symptoms of the effects of smartphone addiction on the body (see Appendix for complete items). These items assess an individual's perception of their health, in relation to SA using a 5-point Likert scale. The total score range is 5-35. A higher score indicates more worse self-health. Items are about the perception of pain in the shoulders, neck, hand joints, muscles, evaluation of lack of exercise, self-awareness of posture problems (sitting and standing), and self-awareness of the effects of vision. In this study, we measured the Kaiser-Meyer-Olkin (KMO) value and Bartlett's test of sphericity. The value of KMO was 0.808 , Bartlett's test of sphericity showed $p<0.001$. At the same time, all items of this factor loaded more than 0.50 . Therefore, this scale was considered to effectively evaluate the participants' self-health, and was suitable for subsequent factor analysis (Tan \& Teo, 1998). This scale is our original. Although it is different from other scales that have been used in various studies. It still shows good internal consistency reliability in subsequent model analysis (Cronbach's alpha $=0.868$ ).

\subsection{Analytical Method}

The study used Microsoft Excel for descriptive statistical analysis of the data. To clarify the impact of SA, the sample was divided into a smartphone addiction group and a non-smartphone addiction group in subsequent analysis.

IBM SPSS 27 was used to analyze the correlation between study variables and a t-test was carried out to judge the significant difference between the two groups. We also checked the KMO value and Bartlett's test of sphericity of the self-health scale to confirm that the scale is suitable for further analysis.

Finally, the partial least square structural equation model (PLS-SEM) of SmartPLS 3.3.2 was used to verify the hypothetical path. PLS-SEM is a data analysis method popular in the field of social sciences to estimate complex causal models between latent variables (Brever, Cinner, Fisher, Green, \& Wilson, 2012; Nitzl \& Chin, 2017). There were two reasons for using PLS-SEM. First, PLS-SEM based on variance shows higher model estimation ability than CB-SEM based on covariance in the theoretical exploration stage (Hair, Ringle, \& Sarstedt, 2014). Second, PLS-SEM supports model prediction for small samples. Generally, the "10-order rule" is the most common sample size estimation method when using PLS-SEM analysis and requires the sample size to be larger than 10 times of the maximum number of internal or external model links pointing to any potential variables in the model (Hair et al., 2014). Therefore, the sample size of 114 in this study satisfies our need for model prediction.

\section{Results}

\subsection{Descriptive Statistics}

The descriptive statistics of the dataset are shown in Table 1 . There were 70 females $(61.40 \%)$ and 44 males $(38.60 \%)$ in the sample. Regarding age, a majority of the people were the 20-29 age group. Participants were also asked about their current residence, 44 of them lived abroad, and 70 lived in China. In addition to students ( $n=41$, 
$35.96 \%)$ the sample also included workers ( $n=73,64.04 \%)$. Moreover, there was a majority of iPhone users in the total sample ( $n=83,72.81 \%)$, and $31(27.19 \%$ of the total sample) were Android users. It should be noted that the education level in the sample was very high, with 50 people whose highest degree was bachelor, and 64 people who had a master's degree or higher.

Table 1. Descriptive statistics for the sample $(\mathrm{N}=114)$

\begin{tabular}{llll}
\hline Item & Category & $\boldsymbol{n}$ & \% \\
\hline \multirow{2}{*}{ Sex } & Male & 44 & 38.60 \\
& Female & 70 & 61.40 \\
\hline \multirow{2}{*}{ Age } & $20-29$ & 93 & 81.58 \\
& $30-39$ & 21 & 18.42 \\
\hline \multirow{2}{*}{ Place } & Live abroad & 44 & 38.60 \\
& Live in China & 70 & 61.40 \\
\hline \multirow{2}{*}{ Job } & Student & 41 & 35.96 \\
& Worker & 73 & 64.04 \\
\hline \multirow{2}{*}{ Education } & Bachelor's Degree & 50 & 43.86 \\
& Master's Degree and Above & 64 & 56.14 \\
\hline \multirow{2}{*}{ Type of Smartphone } & iPhone & 83 & 72.81 \\
\end{tabular}

We also calculated descriptive statistics for each study variable using the built-in data analysis tool; the results are shown in Table 2. The average score for SA was $37.16( \pm 10.30)$ and is clearly higher than the baseline (31 for males, 33 for females). The mean sleep quality was $5.86( \pm 2.80)$, the mean self-rated health was $23.20( \pm 6.32)$, and the mean life satisfaction was $21.24( \pm 6.31)$.

Table 2. Summary of survey variables

\begin{tabular}{lllll}
\hline Item & Mean & SD & Min & Max \\
\hline Smartphone Addiction & 37.16 & 10.30 & 12 & 60 \\
Sleep Quality & 5.86 & 2.80 & 0 & 15 \\
Self-Health & 23.20 & 6.32 & 8 & 35 \\
Life Satisfaction & 21.24 & 6.31 & 5 & 35 \\
\hline
\end{tabular}

\subsection{Correlation Analysis}

Before validating the model, we performed a correlation analysis on the study variables. Table 3 shows the results of the correlation analysis between the variables in the model. Generally, $p<0.05$ indicates that the correlation coefficient is statistically significant. SA was significantly related to self-health $(r=0.59, p<0.001)$ and sleep quality $(r=0.43, p<0.001)$. We also found a significant correlation between self-health and sleep quality $(r=0.47$, $p<0.001)$. However, the correlation between life satisfaction and SA $(r=-0.12, p=0.196)$, self-health $(r=-0.08$, $p=0.38)$, and sleep quality $(r=-0.11, p=0.25)$ were not statistically significant. Overall, SA, self-health, and sleep quality were related to each other, however none of them were related to life satisfaction. 
Table 3. Pearson correlation between study variables

\begin{tabular}{lllll}
\hline & Smartphone Addiction & Self-Health & Sleep Quality & Life Satisfaction \\
\hline Smartphone Addiction & 1 & & & \\
Self-Health & $0.59^{* * *}$ & 1 & & \\
Sleep Quality & $0.43^{* * *}$ & $0.47^{* * *}$ & 1 & 1 \\
Life Satisfaction & -0.12 & -0.08 & -0.11 & 1 \\
\hline
\end{tabular}

Note. Significant correlations $* * *: p<0.001$

\subsection{Hypothesis Testing}

We imported the data into the model established by the above assumptions and conducted a PLS-SEM analysis. In the analysis process, we first confirmed the outer loadings in the model to determine the reliability of the observed items. Generally, the items with outer loadings less than 0.7, or $p>0.05$, should be deleted (Hair, Sarstedt, Ringle, \& Meng, 2011). Thus, we deleted SA1, SA2, SA3, items of SAS-SV; SH7, an item of self-health; and habitual sleep efficiency, sleep duration, sleeping medication, items of PSQI. After this, outer loadings of all factors were greater than 0.7 , and $p<0.05$ (Table 4 ).

Table 4. Outer loading of items

\begin{tabular}{|c|c|c|c|c|c|}
\hline Items & SA & SH & LS & SQ & P value \\
\hline SA4 & 0.714 & & & & 0.000 \\
\hline SA5 & 0.778 & & & & 0.000 \\
\hline SA6 & 0.872 & & & & 0.000 \\
\hline SA7 & 0.766 & & & & 0.000 \\
\hline SA8 & 0.763 & & & & 0.000 \\
\hline SA9 & 0.727 & & & & 0.000 \\
\hline SA10 & 0.718 & & & & 0.000 \\
\hline SH1 & & 0.811 & & & 0.000 \\
\hline SH2 & & 0.863 & & & 0.000 \\
\hline $\mathrm{SH} 3$ & & 0.862 & & & 0.000 \\
\hline SH4 & & 0.704 & & & 0.000 \\
\hline SH5 & & 0.707 & & & 0.000 \\
\hline SH6 & & 0.711 & & & 0.000 \\
\hline LS1 & & & 0.844 & & 0.000 \\
\hline LS2 & & & 0.774 & & 0.000 \\
\hline LS3 & & & 0.898 & & 0.001 \\
\hline LS4 & & & 0.712 & & 0.000 \\
\hline LS5 & & & 0.804 & & 0.000 \\
\hline Sleep Latency & & & & 0.753 & 0.001 \\
\hline Step Disturbance & & & & 0.739 & 0.000 \\
\hline Subjective Sleep Quality & & & & 0.715 & 0.000 \\
\hline Daytime Dysfunction & & & & 0.788 & 0.000 \\
\hline
\end{tabular}

Note. SA: smartphone addiction, SQ: sleep quality, SH: self-health, LS: life satisfaction.

We then evaluated the scales' construct reliability and validity. Many scholars believe that multiple methods should be used to measure internal consistency. The method most often used to measure internal consistency is to 
evaluate Cronbach's alpha coefficient, composite reliability (CR), and rho_A; a value above the threshold of 0.7 is considered acceptable (Hashiguchi et al., 2020). In addition, we also observed the average variance extracted (AVE) to evaluate the variables' convergent validity; the AVE value should be greater than 0.5 (Hair et al., 2014). As can be seen in Table 5 all the values meet the required threshold, therefore, we believe that the scales used in the study exhibit satisfactory construct reliability and validity.

Table 5. The values of construct reliability and validity

\begin{tabular}{llllc}
\hline Variables & AVE & CR & rho_A & Cronbach's Alpha \\
\hline LS & 0.654 & 0.904 & 0.941 & 0.881 \\
SA & 0.584 & 0.907 & 0.893 & 0.881 \\
SH & 0.608 & 0.902 & 0.871 & 0.868 \\
SQ & 0.561 & 0.836 & 0.749 & 0.741 \\
\hline
\end{tabular}

Note. SA: smartphone addiction, SQ: sleep quality, SH: self-health, LS: life Satisfaction, AVE: average variance extracted, CR: composite reliability.

Finally, we analyzed the path coefficients of the model and verified the hypotheses. The model path analysis measure requires the path to have a $t$ statistic greater than 1.96 or a $p$ value less than 0.05 . The path coefficient from SA to sleep quality was $0.441(t=6.112, p<0.001)$, SA to self-health was $0.320(t=3.543, p<0.001)$ and from sleep quality to self-health was $0.420(t=5.626, p<0.001)$. All were therefore considered statistically significant. This means $\mathrm{H}_{1}, \mathrm{H}_{3}$, and $\mathrm{H}_{4}$ were supported. However, none of the paths pointing to life satisfaction were statistically significant. The path coefficients for the three paths initiated from SA, sleep quality, and self-health to life satisfaction were $-0.153(t=0.930, p=0.352), 0.053(t=0.258, p=0.797)$, and $-0.029(t=0.183, p=0.855)$, respectively. This means that $\mathrm{H}_{2}, \mathrm{H}_{5}$, and $\mathrm{H}_{6}$ were not supported. The results are shown in Figure 2 and Table 6.

SmartPLS supports model fit checking by using standardized root mean square residual (SRMR). A value of SRMR less than 0.10 or 0.08 is considered a good fit (Hu \& Bentler, 1998). In this study, the value of SRMR was 0.86; thus, the model fit was considered to be accepted, and it is close to the optimal threshold.

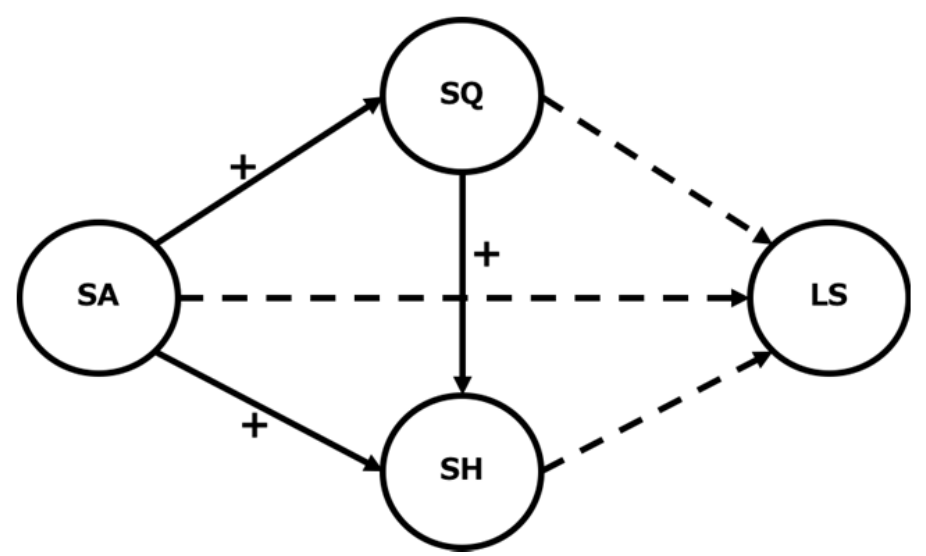

Figure 2. Result of the study Model

Note. SA: smartphone addiction, SQ: sleep quality, SH: self-health, LS: life satisfaction 
Table 6. Result of Hypothesis

\begin{tabular}{lllll}
\hline Path & Path coefficients & $\boldsymbol{t}$ statistic & $\boldsymbol{P}$ value & Hypotheses \\
\hline $\mathrm{SA} \rightarrow \mathrm{SQ}\left(\mathrm{H}_{1}\right)$ & $\mathbf{0 . 4 4 1}$ & $\mathbf{6 . 1 1 2}$ & $\mathbf{0 . 0 0 0}$ & Supported \\
$\mathrm{SQ} \rightarrow \mathrm{LS}\left(\mathrm{H}_{2}\right)$ & 0.053 & 0.258 & 0.797 & Not supported \\
$\mathrm{SQ} \rightarrow \mathrm{SH}\left(\mathrm{H}_{3}\right)$ & $\mathbf{0 . 4 2 0}$ & $\mathbf{5 . 6 2 6}$ & $\mathbf{0 . 0 0 0}$ & Supported \\
$\mathrm{SA} \rightarrow \mathrm{SH}\left(\mathrm{H}_{4}\right)$ & $\mathbf{0 . 3 2 0}$ & $\mathbf{3 . 5 4 3}$ & $\mathbf{0 . 0 0 0}$ & Supported \\
$\mathrm{SH} \rightarrow \mathrm{LS}\left(\mathrm{H}_{5}\right)$ & -0.029 & 0.183 & 0.855 & Not supported \\
$\mathrm{SA} \rightarrow \mathrm{LS}\left(\mathrm{H}_{6}\right)$ & -0.153 & 0.930 & 0.352 & Not supported \\
\hline
\end{tabular}

Note. SA: smartphone addiction, SQ: sleep quality, LS: Life satisfaction, SH: self-health.

\subsection{Significant Difference Testing}

To understand the impact of SA on life more intuitively, we divided the sample into a smartphone addiction group (Yes, $n=79,69.3 \%$ ) and a non-smartphone addiction group (No, $n=35,30.7 \%$ ) according to their scores on the SAS-SV and compared the significance of the differences in their mean scores on the remaining three scales. The results are shown in Figure 3. The results showed that the non-smartphone addiction group showed lower sleep quality $(t=-2.72, p=0.01)$ and self-health $(t=-4.45, p<0.001)$ scores than the smartphone addiction group, and the difference between the two groups was statistically significant. This means that the smartphone addiction group showed worse sleep quality and self-health. There was no statistically significant difference between the two groups $(t=1.09, p=0.28)$ in terms of life satisfaction.
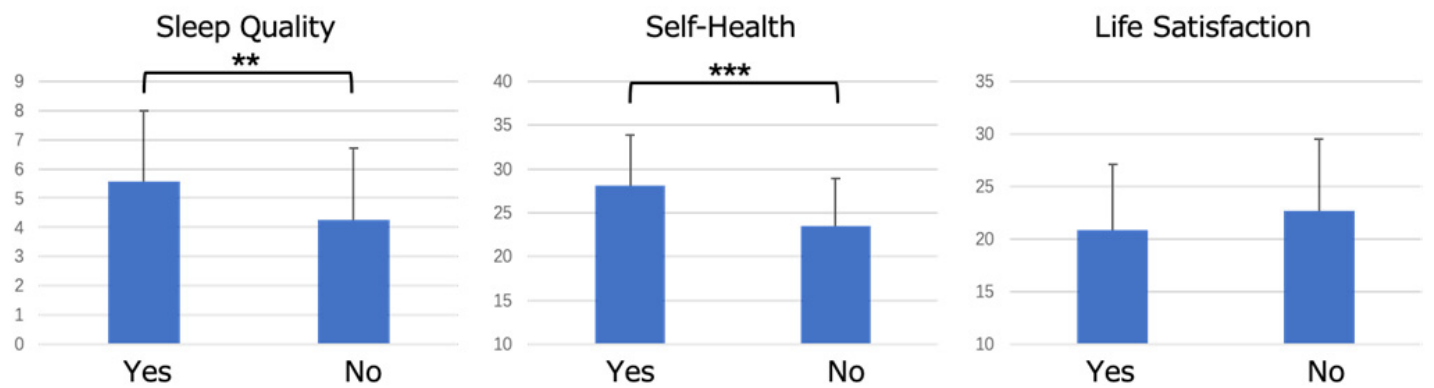

Figure 3. t-test between smartphone addiction group (Yes) and non-smartphone addiction group (No)

Note. Significant correlations ${ }^{* * *}: p<0.001, * *: p<0.01$.

\section{Discussion}

From the above analysis, we conclude that SA does not always have a negative impact on life satisfaction. In addition, no mediating effect of sleep quality or self-health was found.

In this study, we formed six hypotheses to explore the mediating role of sleep quality and self-health in SA and life satisfaction. According to the analyses, the results supported some of the hypotheses. Since their path coefficients were statistically significant, $\mathrm{H}_{1}$ and $\mathrm{H}_{3}$ proved that $\mathrm{SA}$ has a direct impact on sleep quality and self-health and that the higher the SA, the worse the sleep quality and self-health. $\mathrm{H}_{4}$, which was supported through the results, suggests that sleep problems caused by SA also have a direct negative impact on self-health. In addition, there were statistically significant differences in sleep quality scores and self-rated health scores between the smartphone addiction and non-smartphone addiction groups. This conclusion is of particular social significance. A survey conducted in 2014 showed a general downward trend in the physical fitness of university students, the detection rate of poor eyesight tends to be younger, and an increasing rate of obesity detection (General Administration of Sport of China, 2014). Moreover, a survey on the physical fitness and physical activity of 1,414 students at Tsinghua University also indicated that $75.9 \%$ of men and $79.8 \%$ of women exercise less than three times a week (Wang, 2019). This study's conclusions point out that SA and sleep quality are the direct causes of health effects. Therefore, universities and institutions need to pay attention to SA among college students. We believe that measures of universities that intervene in the excessive use of smartphones are effective means to improve the 
physical fitness of college students. For example, some universities' campus networks restrict access to mobile phones and computer games and suspend the campus network after $10 \mathrm{pm}$.

Nevertheless, SA and the problems of sleep quality and self-health caused by SA had no direct effect on life satisfaction. Additionally, in the correlation analysis, no correlation between SA, sleep quality and self-health and life satisfaction was found. This finding is contrary to the findings of some previous studies. For example, one study indicated that reduced sleep quality had a direct negative impact on life satisfaction (Li, Lepp, \& Barkley, 2015). The reason for this difference may be due to differences in sample characteristics. Li et al.'s sample was majorly composed of Americans, while the sample of this study is Chinese. Cultural differences may lead to different smartphone usage habits, so we speculate that there may be geographic differences in the effect of reduced sleep quality caused by smartphones on life satisfaction.

However, the results of this study also support previous studies. For example, the study done by Lepp and colleagues (2014) also did not find a correlation between SA and life satisfaction and another by David et al. (2018) found that certain apps were positively correlated with well-being. Therefore, future research on the relationship between SA and life satisfaction should consider additional variables, such as differences in smartphone use habits.

\section{Limitations}

Some limitations of this study should be noted. This sample had a high SA rate of $69.3 \%$. Therefore, the sample was unique and might have influence the results. However, we speculate that the experience of studying abroad may affect SA. Some preliminary studies support our speculation. For example, a survey of 438 international students in China showed that international students are at high risk of SA and that loneliness is a key factor of SA. (Jiang, Li \& Shypenka, 2018). In fact, loneliness is a severe problem faced by international students (Wawera \& McCamley, 2019; Sawir, Marginson, Deumert, Nyland \& Ramia, 2008; Dutta \& Chye, 2017). In the 5G era, applications on smartphones are extensive, and due to globalization, an increasing number of people will study and work overseas. In this context, it is necessary to pay attention to the effects of SA on people who live abroad. Therefore, we encourage more researchers to explore this field to promote the judicious use of smartphones.

This study uses only self-reported data. Boase and Ling (2013) believe that such reports are inherently unreliable and that there is a need to collect actual smartphone usage data to support them. In fact, with the proliferation of smartphone applications, there are already many applications on the market that can be used to collect objective data. For example, a study by David and colleagues (2018) uses a new iPhone feature to detect the time spent on a smartphone. This function automatically detects the smartphone user's usage data, such as the time spent on the smartphone, the time spent on various devices, and the time spent each application, smartphone reminder times, etc. In addition, some applications that can detect the health of smartphone users are emerging. We suggest that empirical research on known theoretical models should be conducted by collecting objective data.

Another limitation of this study is that the participants were only asked survey questions regarding the past month of their lives. In particular, the data collection period for this study was between February 7 and February 10, 2020. During that period, participants experienced the Chinese New Year (January 25, 2020), which is the biggest festival in China, and additionally the COVID-19 outbreak. This special situation may also cause deviations in the results. Therefore, the results of this study cannot be generalized to other contexts and time periods; more longitudinal studies should be conducted in the future.

\section{Conclusion}

The conclusions of this research provide two important contributions to the rational use of smartphones. On the one hand, this study proved that the direct negative impact of smartphone addiction on life satisfaction is not absolute. Therefore, we suggest that in future research to explore the relationship between smartphone addiction and life satisfaction, more influencing factors should be considered, such as different smartphone usage habits among different regions. And use objective data other than questionnaire surveys for theoretical verification. On the other hand, this research confirms that smartphone addiction does lead to poor sleep quality and self-health. This result should arouse our vigilance. Nowadays, smartphones have become an inseparable part of our daily lives, especially in countries with high smartphone penetration rates. Therefore, the correct and reasonable use of smartphones becomes crucial.

\section{Research Ethics Considerations}

Since this research is a questionnaire survey with human, the research plan was checked before the research was conducted in accordance with the regulations on ethics for research on human of Ritsumeikan University (http://www.ritsumei.ac.jp/research/approach/ethics/mankind/), to which the researchers belong by using checklist (http://www.ritsumei.ac.jp/file.jsp?id=397250\&f=.doc). As a result, it was confirmed that there was no need to 
apply to the IRB for our research plan.

\section{Acknowledgments}

This research was financially supported by the Ministry of Land, Infrastructure, Transport and Tourism (FY2019FY2020 research and development for construction technology subsidy program policy issue solving type Analytical evaluation system for improving productivity using lifelog information in unmanned construction). In addition, this work was supported by the FFJ/Air Liquide Fellowship. The author gratefully acknowledges the generous support and assistance of the Fondation France-Japon (FFJ) de Ecole des Hautes Etudes en Sciences Sociales (EHESS) and Air Liquide. The authors would like to express their sincere thanks to all the respondents who participated in the survey of this study.

\section{Competing Interests Statement}

The authors declare that there are no conflicts of interest.

\section{References}

Adams, S. K. \& Kisler, T. S. (2013). Sleep quality as a mediator between technology-related sleep quality, depression, and anxiety. Cyberpsychology Behavior Social Networking, 16(1), 25-30. https://doi.org/10.1089/cyber.2012.0157

Alwashmi, M. F., Fitzpatrick, B., Farrell, J., Gamble, J. M., Davis, E., Nguyen, H. V., ... Hawboldt, J. (2020). Perceptions of patients regarding mobile health interventions for the management of chronic obstructive pulmonary disease: mixed methods study. JMIR mHealth and uHealth, 8(7): e17409. https://doi.org/10.2196/17409

Ayas N. T., White D. P., Al-Delaimy W. K., Manson J. E., Stampfer M. J., Speizer F. E., ... Hu F. B. (2003). A prospective study of self-reported sleep duration and incident diabetes in women. Diabetes Care, 26(2), 380-384. https://doi.org/10.2337/diacare.26.2.380

Bentley, C. L., Powell, L., Potter, S., Parker, J., Mountain, G. A., Bartlett, Y. K., ... Hawley, M. S. (2020). The use of a smartphone app and an activity tracker to promote physical activity in the management of chronic obstructive pulmonary disease: randomized controlled feasibility study. JMIR mHealth and uHealth, $8(6)$ : e16203. https://doi.org/10.2196/16203

Berolo, S., Wells, R. R., \& Amick, B. C. (2011). Musculoskeletal symptoms among mobile hand-held device users and their relationship to device use: A preliminary study in a Canadian university population. Applied Ergonomics, 42(2), 371-378. https://doi.org/10.1016/j.apergo.2010.08.010

Boase, J., \& Ling, R. (2013). Measuring mobile phone use: self-report versus log data. Journal of Computer-Mediated Communication, 18(4), 508-519. https://doi.org/10.1111/jcc4.12021

Boonstra, A. M., Reneman, M. F., Stewart, R. E., Post, M. W., \& Preuper, H. R. S. (2013). Life satisfaction in patients with chronic musculoskeletal pain and its predictors. Quality of Life Research, 22, 93-101. https://doi.org/10.1007/s11136-012-0132-8

Brewer, T., Cinner, J. E., Fisher, R., Green, A., \& Wilson, S. K. (2012). Market access, population density, and socioeconomic development explain diversity and functional group biomass of coral reef fish assemblages. Global Environmental Change, 22(2), 399-406. https://doi.org/10.1016/j.gloenvcha.2012.01.006

Buysee, D. J., Reynolds, C. F., Monk, T. H., Berman, S. R., \& Kupfer, D. J. (1989). The Pittsburgh Sleep Quality Index - a new instrument for psychiatric practice and research. Psychiatry Research, 28(2), 193-213. https://doi.org/10.1016/0165-1781(89)90047-4

Calamaro, C. J., Mason, T. B. A., \& Ratcliffe, S. J. (2009). Adolescents living the 24/7 lifestyle: effects of caffeine and technology on sleep duration and daytime functioning. Pediatrics, 123(6), 1005-1010. https://doi.org/10.1542/peds.2008-3641

Callan, J. A., Jacob, J. D., Siegle, G. J., Dey, A., Thase, M. E., Dabbs, A.D., ... Sereika, S. (2020). CBT MobileWork (c): user-centered development and testing of a mobile mental health application for depression. Cognitive Therapy and Research. https://doi.org/10.1007/s10608-020-10159-4

Cappuccio, F. P., Stranges, S., Kandala, N. B., Miller, M. A., Taggart, F. M., Kumari, M., ... Marmot, M.G. (2007). Gender-specific associations of short sleep duration with prevalent and incident hypertension. Hypertension, 50(4), 693-700. https://doi.org/10.1161/HYPERTENSIONAHA.107.095471

Cappuccio, F. P., D'Elia, L., Strazzlillo, P., \& Miller, M. A. (2010). Quantity and quality of sleep and incidence of 
type 2 diabetes - A systematic review and meta-analysis. Diabetes Care, 33(2), 414-420. https://doi.org/10.2337/dc09-1124

Custers, K., \& Van den Bulck, J. (2012). Television viewing, internet use, and self-reported bedtime and rise time in adults: implications for sleep hygiene recommendations from an exploratory cross-sectional study. Behavior Sleep Medicine, 10(2), 96-105. https://doi.org/10.1080/15402002.2011.596599

David, M. E., Roberts, J. A., \& Christenson, B. (2018). Too much of a good thing: investigating the association between actual smartphone use and individual well-being. International Journal of Human-Computer Interaction, 34(3), 265-275. https://doi.org/10.1080/10447318.2017.1349250

Davies, M. (2015). Average person now spends more time on their phone and laptop than SLEEPING, study claims. Retrieved

from http://www.dailymail.co.uk/health/article-2989952/how-technology-taking-lives-spend-tim

Dharmadhikari, S. R., Harshe, S. D., \& Bhide, P. P. (2019). Prevalence and correlates of excessive smartphone use among medical students: A cross-sectional study. Indian Journal of Psychology Medicine, 41(6), 549-555. https://doi.org/10.4103/IJPSYM.IJPSYM_75_19

Diener, E., Emmons, R. A., Larsen, R. J., \& Grrifin, S. (1985) The satisfaction with life scale. Journal of Personality Assement, 49(1), 71-75. https://doi.org/10.1207/s15327752jpa4901_13

Diener, E., Suh, E. M., Lucas, R. E., \& Smith, H. L. (1999) Subjective well-being: Three decades of progress. Psychological Bulletin, 125(2), 276-302. https://doi.org/10.1037//0033-2909.125.2.276

Dutta, O., \& Chye, S. Y. L. (2017). Internet use and psychological wellbeing: A study of international students in Singapore. Journal of International Students, 7(3), 825-840. https://doi.org/10.5281/zenodo.570036

Fossum, I. N., Nordnes, L. T., Storemark, S. S., Bjorvatn, B., \& Pallesen, S. (2014). The association between use of electronic media in bed before going to sleep and insomnia symptoms, daytime sleepiness, morningness, and chronotype. Behavior Sleep Medicine, 12(5), 343-357. https://doi.org/10.1080/15402002.2013.819468

Gangwisch, J. E., Heymsfield, S. B., Boden-Albala, B., Buijs, R. M., Kreier, F., Pickering, T. G., ... Malaspina D. (2006). Short sleep duration as a risk factor for hypertension - Analyses of the first national health and nutrition examination survey. Hypertension, 47(5), 833-839. https://10.1161/01.HYP.0000217362.34748.e0

General Administration of Sport of China, (2014). Report of National Student Fitness Test and Health Survey Results in 2014. Retrieved from http://www.sport.gov.cn/n16/n1077/n1227/7328990.html

Gottlieb, D. J., Redline, S., Nieto, F. J., Baldwin, C. M., Newman, A. B., Resnick, H. E., \& Punjabi, N. M. (2006). Association of usual sleep duration with hypertension: The sleep heart health study. Sleep, 29(8), 1009-1014. https://10.1093/sleep/29.8.1009

Hair, J. F., Ringle, C. M., \& Sarstedt, M. (2014). PLS-SEM: Indeed a silver bullet. Journal of Marketing Theory and Practice, 19(2), 139-151. https://doi.org/10.2753/MTP1069-6679190202

Hair, J. F., Sarstedt, M., Ringle, C. M., \& Meng, J. A. (2011). An assessment of the use of partial least squares structural equation modeling in marketing research. Journal of the Academy of Marketing Science, 40, 414-433. https://doi.org/10.1007/s11747-011-0261-6

Hashiguchi, N., Cao, J. F., Lim, Y. J., Kubota, Y., Kitahara, S., Ishida, S., \& Kodama K. (2020). The effects of psychological factors on perceptions of productivity in construction sites in Japan by worker age. International Journal of Environmental Research and Public Health, 17(10). https://doi.org/10.3390/ijerph17103517

Hu, L. T., \& Bentler, P. M. (1998). Fit indices in covariance structure modeling: Sensitivity to underparameterized model misspecification. Psychological Methods, 3(4), 424-453. https://doi.org/10.1037/1082-989X.3.4.424

Hughes, N., \& Burke, J. (2018). Sleeping with the frenemy: How restricting 'bedroom use' of smartphones impacts happiness and wellbeing. Computers in Human Behavior, 85, 236-244. https://doi.org/10.1016/j.chb.2018.03.047

Jiang, Q. L., Li, Y., \& Shypenka, V. (2018). Loneliness, individualism, and smartphone addiction among international students in China. Cyberpsychology Behavior and Social Networking, 21(11), 711-718. https://doi.org/10.1089/cyber.2018.0115

Jovanovic, V. (2016). The validity of the Satisfaction with Life Scale in adolescents and a comparison with single-item life satisfaction measures: a preliminary study. Quality of Life Research, 25(12), 3173-3180. 
https://doi.org/10.1007/s11136-016-1331-5

Jung, S. I., Lee, N. K., Kang, K. W., Kim, K., \& Lee, D. Y. (2016). The effect of smartphone usage time on posture and respiratory function. Journal of Physical Therapy Science, 28(1), 186-189. https://doi.org/10.1589/jpts.28.186

Kim, S. E., Kim, J. W., \& Jee, Y. S. (2015). Relationship between smartphone addiction and physical activity in Chinese international students in Korea. Journal of Behavior Addiction, 4(3), 200-205. https://doi.org/10.1556/2006.4.2015.028

Konok, V., Pogany, A., \& Miklosi, A. (2017). Mobile attachment: Separation from the mobile phone induces physiological and behavioural stress and attentional bias to separation-related stimuli. Computers in Human Behavior, 77, 228-239. https://doi.org/10.1016/j.chb.2017.02.002

Kwon, M., Kim, D. J., Cho, H., \& Yang, S. (2013). The Smartphone Addiction Scale: development and validation of a short version for adolescents. Plos One, 8(12). https://doi.org/10.1371/journal.pone.0083558

Kwon, M., Lee, J. Y., Won, W. Y., Park, J. W., Min, J. A., Hahn, C., ... Kim, D. J. (2013). Development and validation of a Smartphone Addiction Scale (SAS). Plos One, $8(2)$. https://doi.org/10.1371/journal.pone.0056936

Lanaj, K., Johnson, R. E., \& Barnes C. M. (2014). Beginning the workday yet already depleted? Consequences of late-night smartphone use and sleep. Organizational Behavior and Human Decision Processes, 124(1), pp. 11-23. https://doi.org/10.1016/j.obhdp.2014.01.001

Lee, S., Kang, H., \& Shin, G. (2015). Head flexion angle while using a smartphone. Ergonomics, 58(2), 220-226. https://doi.org/10.1080/00140139.2014.967311

Lemola, S., Perkinson-Gloor, N., Brand, S., Dewald-Kaufmann, J. F., \& Grob, A. (2015). Adolescents' electronic media use at night, sleep disturbance, and depressive symptoms in the smartphone age. Journal of Youth and Adolescence, 44(2), 405-418. https://doi.org/10.1007/s10964-014-0176-x

Lepp, A., Barkley, J. E., \& Karpinski, A. C. (2014). The relationship between cell phone use, academic performance, anxiety, and Satisfaction with Life in college students. Computers in Human Behavior, 31, 343-350. https://doi.org/10.1016/j.chb.2013.10.049

Li, J., Lepp, A., \& Barkley, J. E. (2015). Locus of control and cell phone use: Implications for sleep quality, academic performance, and subjective well-being. Computers in Human Behavior, 52, 450-457. https://doi.org/10.1016/j.chb.2015.06.021

Litwic-Kaminska, K., \& Kotysko, M. (2017). Comparison of good and poor sleepers: stress and life satisfaction of university athletes. Revista De Osicologia Del Deporte, 26(4), 121-126.

Majchrzak, A., Beath, C. M., Lim, R. A., \& Chin, W. W. (2005). Managing client dialogues during information systems design to facilitate client learning. MIS Quarterly, 29(4), pp. 653-672.

Misra, S., Cheng, L. L., Genevie, J., \& Yuan, M. (2016). The iPhone effect: The quality of in-person social interactions in the presence of mobile devices. Enviroment and Behavior, 48(2), 275-298. https://doi.org/10.1177/0013916514539755

Munezawa, T., Kaneita, Y., Osaki, Y., Kanda, H., Minowa, M., Suzuki, K., ... Ohida, T. (2011). The association between use of mobile phones after lights out and sleep disturbances among Japanese adolescents: A nationwide cross-sectional survey. Sleep, 34(8), 1013-1020. https://doi.org/10.5665/SLEEP.1152

National Sleep Foundation. (2011). 2011 Sleep in America poll: Communications Technology in the Bedroom. Retrieved from https://www.sleepfoundation.org/sites/default/files/inline-files/SIAP_2011_Summary_of_Findings.pdf

Nie, J., Wang, P.C., \& Lei, L. (2020). Why can't we be separated from our smartphones? The vital roles of smartphone activity in smartphone separation anxiety. Computers in Human Behavior, 109. https://doi.org/10.1016/j.chb.2020.106351

Nitzl, C., \& Chin, W. W. (2017). The case of partial least squares (PLS) path modeling in managerial accounting research. Journal of Management, 28, 137-156. https://doi.org/10.1007/s00187-017-0249-6

Phu, B., \& Gow, A. J. (2019). Facebook use and its association with subjective happiness and loneliness. Computers in Human Behavior, 92, 151-159. https://doi.org/10.1016/j.chb.2018.11.020

Przybylski, A. K., \& Weinstein, N. (2013). Can you connect with me now? How the presence of mobile 
communication technology influences face-to-face conversation quality. Journal of Social and Personal Relationships, 30(3), 237-246. https://doi.org/10.1177/0265407512453827

Rezaei, A., \& Jeddi, E. M. (2020). Relationship between wisdom, perceived control of internal states, perceived stress, social intelligence, information processing styles and life satisfaction among college students. Current Psychology, 39(3), 927-993. https://doi.org/10.1007/s12144-018-9804-z

Samaha, M., \& Hawi, N. S. (2016) Relationships among smartphone addiction, stress, academic performance, and satisfaction with life. Computers in Human Behavior, 57, 321-325. https://doi.org/10.1016/j.chb.2015.12.045

Sawir, E., Marginson, S., Deumert, A., Nyland, C., \& Ramia, G. (2008). Loneliness and international students: an Australian study. Journal of Studies in International Education, 12(2), 148-180. https://doi.org/10.1177/1028315307299699

Shaffer, H. J. (1996). Understanding the means and objects of addiction: Technology, the internet, and gambling. Journal of Gambling Studies, 12(4), pp. 461-469. https://doi.org/10.1007/BF01539189

Sharan, D., Mohandoss M., Ranganathan R., \& Jose J. (2014). Musculoskeletal disorders of the upper extremities due to extensive usage of handheld devices. Annals of Occupational and Environmental Medicine, 26 (1). https://doi.org/10.1186/s40557-014-0022-3

Tamura, H., Nishida, T., Tsuji, A., \& Sakakibara, H. (2017). Association between excessive use of mobile phone and insomnia and depression among Japanese adolescents. International Journal of Environmental Research and Public Health, 14(7): 701. https://doi.org/10.3390/ijerph14070701

Tan, M., \& Teo, T. S. (1998). Factors influencing the adoption of the internet. International Journal of Electronic Commerce, 2(3), 5-18. https://doi.org/10.1080/10864415.1998.11518312

Volkmer, S. A., \& Lermer, E. (2019) Unhappy and addicted to your phone? - Higher mobile phone use is associated with lower well-being. Computers in Human Behavior, 93, 210-218. https://doi.org/10.1016/j.chb.2018.12.015

Wang, J. L. (2019). The association between physical fitness and physical activity among Chinese college students. Journal of American College Health, 67(6), 602-609. https://doi.org/10.1080/07448481.2018.1515747

Wawera, A. S., \& McCamley, A. (2019). Loneliness among international students in the UK. Journal of Further and Higher Education, 44(9), pp. 1262-1274. https://doi.org/10.1080/0309877X.2019.1673326

Wilcockson, T. D. W., Osborne, A. M., \& Ellis, D. A. (2019). Digital detox: The effect of smartphone abstinence on mood, anxiety, and craving. Addictive Behaviors, 99: 106013. https://doi.org/10.1016/j.addbeh.2019.06.002

Zaid, N. H. M., Rahman, N. A. A., \& Haque, M. (2018). The association between sleep quality and well-being amongst allied health sciences students in a public university in Malaysia. Advances in Human Biology, 8(3), 195-200. https://10.4103/AIHB.AIHB_22_18

\section{Appendix}

\section{The questionnaires of survey}

\begin{tabular}{|c|c|}
\hline \multirow{8}{*}{$\begin{array}{c}\text { Smartphone } \\
\text { Addiction Scale } \\
\text { (SAS-SV) }\end{array}$} & SA1: Missing planned work due to smartphone use. \\
\hline & $\begin{array}{l}\text { SA2: Having a hard time concentrating in class, while doing assignments, or while } \\
\text { working due to smartphone use. }\end{array}$ \\
\hline & SA3: Feeling pain in the wrists or at the back of the neck while using a smartphone. \\
\hline & SA4: Won't be able to stand not having a smartphone. \\
\hline & SA5: Feeling impatient and fretful when I am not holding my smartphone. \\
\hline & SA6: Having my smartphone in my mind even when I am not using it. \\
\hline & $\begin{array}{l}\text { SA7: I will never give up using my smartphone even when my daily life is already greatly } \\
\text { affected by it. }\end{array}$ \\
\hline & $\begin{array}{l}\text { SA8: Constantly checking my smartphone so as not to miss conversations between other } \\
\text { people on Twitter or Facebook. }\end{array}$ \\
\hline
\end{tabular}




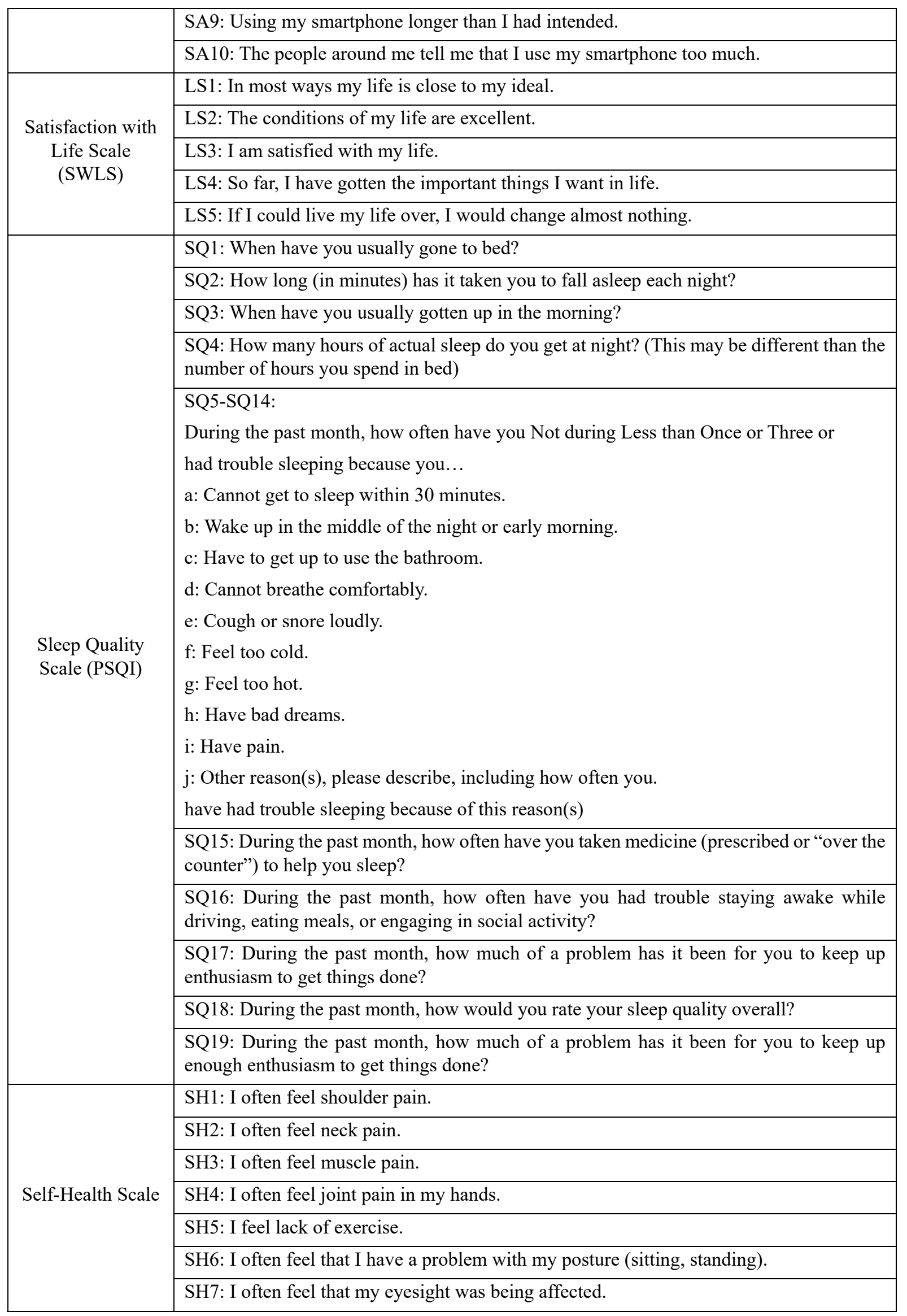




\section{Copyrights}

Copyright for this article is retained by the author(s), with first publication rights granted to the journal.

This is an open-access article distributed under the terms and conditions of the Creative Commons Attribution license (http://creativecommons.org/licenses/by/4.0/). 